\title{
Johaianés die Doper in Betanië oorkant die Jordaan
}

\author{
SJ Nortie \\ Randse Afrikaanse Uniyersiteit
}

\begin{abstract}
John the Baptist in Bethany across the Jordan

There are two places in the Fourth Gospel called 'Bethany'. One is the well-known site near Jerusalem. The other is the lesser-known locality where John the Baptist started his career as the 'Baptist'. This paper traces John's use of 'Bethany across the Jordan'. It is contended that the site has more than geographical significance. In analysis the theological purpose of the site is demonstrated. It is the spot where the two Johannine worlds meet: The world above and the world below. This Johannine dualism is resolved at one spesific time and place, viz at this Bethany. The locality therefore has the theological significance as point of departure for the narration of the coming of Gods onlybegotten son, who is the Lamb of God, who takes away the sin of the world.
\end{abstract}

\section{INLEIDING}

Om Johannes die 'Doper' op voetspoor van die Vierde Evangelie te volg, is 'n belewenis van sy eie. Hoe weinig hoef ons na biografiese brokkies te soek om die legkaart te voltooi. Om na hom te soek, is om na hom te luister want al wat hy gedoen het, is om te getuig. Wat die outeur/verteller van tradisies tot sy beskikking gehad het, het hy so gebruik dat ons 'n skets het van die man wat hy gebruik het om die toneel voor te berei vir die verskyning van Jesus, die Lam.

Sonder aankondiging, kom daar 'n stem uit die woestyn: 'Maak die pad vir die Here reguit' (Joh 1: 23). Die weg deur die woestyn loop van Jesaja (40: 3) na Johannes, so word hy 'n Jesaja-redivivus. En die plek waar dit alles gebeur het, is by 'Betanië oorkant die Jordaan' (Joh 1: 28). Later skuif die toneel na 'Enon naby 
Salim', 'n waterryke plek erens naby Nablus in Samaritaanse grondgebied (Bruce 1983: 93). Dit is egter nie hierdie plek wat in die gemoed van die verteller vasgehaak het nie, dit is die 'plek oorkant die Jordaan', waar die 'Lam van God' aan die wêreld voorgestel is, en niks minder nie as op die bestel van God.

Die Vierde Evangelie vermeld twee plekke wat die naam Betanië dra: Die plek waar Johannes gedoop en opgetree het en die dorp waar Jesus se drie vriende Maria, Marta en Lasarus gewoon het. In hierdie artikel wil ons nagaan wat die narratologiese betekenis van Johannes se optrede in Betanië oorkant die Jordaan is.

\section{BETANIẽ OORKANT DIE JORDAAN (JOH 1: 28; 3: 26; 10: 39-42)}

\section{In Betaniē: Johannes 1: 28}

Dit is meer as geografiese belangstelling wat ons laat vra presies waar Johannes gedoop het. Die plek word slegs een keer genoem (Joh 1: 28). Die oudste en waarskynlik mees outentieke teks lees hier 'Bethania'. Barrett (1972: 146) dui die vernaamste teksvariante aan. Die keuse le tussen 'Bethania' en 'Bethabara'. Origenes, in sy uitgebreide reise in Palestina, was nie in staat om 'n Betanië by die Jordaan te vind nie. In verskillende manuskripte van sy tyd het hy egter die naam 'Bethabara' as doopplek opgespoor. Op grond hiervan en ou tradisies wat hy teengekom het oor laasgenoemde lesing, het hy etimologiese afleidings gemaak, en toe bestuit:

The ethimology of the name [Bethabara] corresponds with the baptism of him who made ready for the Lord a people prepared for him; for it yields the meaning "House of preparation", while Bethany means "House of obedience". Where else was it fitting that he should baptize, who was sent as a messenger before the face of Christ ... but at the "House of Preparation" (aangehaal in Metzger 1975: 199-200).

Ten spyte hiervan is die sterker lesing tog Betanië, 'n lesing wat reeds in Origenes se tyd, 'n honderd jaar na die Evangelie se totstandkoming in omloop was.

Aan etimologiese en simboliese konnotasies het ons te weinig om die plek en sy betekenis te bepaal. Eweneens is dit te yl om te beweer dat die Historizität der Erzählung wird gesichert durch die Angabe des Ortes (Schneider 1978: 68). Dat die naam slegs 'n historiese anker vir die vertelling oor Johannes sou wees (vgl Ridderbos 1987: 86 en talle ander), is 'n standpunt wat steun op 'n fundamenteethistoriese vertolking van die Evangelie. Dat daar reeds 'n honderd jaar na die 
gebeure twyfel bestaan het oor die pleknaam en plekbepaling, is 'n aanduiding dat ons na meer moet gaan soek as 'n blote historiese verankering van die gebeure.

Reeds in 1911 het Dibelius (1911: 108) gesé: 'We must not seek historical references in this passage, for apart from the reminiscence of a saying of the Baptist in 1: $26 \mathrm{f} \ldots$ the single historical items in the entire pericope is probably only the originally close tie between the two movements, Johannine and Christian ...' (aangehaal deur Haenchen 1984: 147). Of die naam Betonim wat ons in Josua 13:6 vind, topografies met die plek van die doop verbind kan word, is irrelevant. Die Vierde Evangelis heg ' $n$ ander betekenis aan sy tyd-en plekaanduidings.

Vergelyk ons die Evangelis se kort en vae beskrywing van tyd en plek met die vergelykbare parallelle in Lukas, is die verskil opvallend. Lukas gee 'n swak plekbeskrywing, maar ' $n$ uiters volledige tydsbepaling: 'Dit was die vyftiende regeringsjaar van keiser Tiberius. Pontius Pilatus was goewerneur van Judea, en Herodes heerser van Galilea, sy broer Filippus van Iturea en Tragoritis, en Lisanias heerser van Abilene. Annas en Kajafas was die hoeppriesters. In daardie tyd het die Woord van God tot Johannes, seun van Sagaria in die woestyn gekom ...' (Luk 3: 12a). Indien daar ooit van 'n historiese anker gepraat kan word, is dit hier! Lukas wou seker maak dat sy lesers presies weet wanneer hierdie gebeure plaasgevind het. Waar dit plaasgevind het, is vir hom 'in die woestyn', 'n onbekende plek.

Dit is ook die geval in die ander twee Sinoptiese Evangelies. Matteus vertel iets meer, dat dit naamlik in 'die woestyn van Judea plaasgevind het (Matt 3: 1). Markus, is soos Lukas, tevrede om Johannes se eerste optrede 'in die woestyn' te laat plaasvind (Mark 1: 4). Nietemin, die woestyn bly 'n groot en onberekenbare plek.

Dat dit juis Johannes, die mees 'geestelike' Evangelie (in die sin van bo tyd en ruimte verhewe) is wat weet wat die naam van die plek in die woestyn was, is te opvallend en ingrypend om as 'n terloopse historiese vermelding verklaar te kan word. Dit geld ook van sy tydaanduidings. Ons lees van die 'volgende dag' (Joh 1: 29) ... die 'volgende dag' (Joh 1:35) 'daardie hele dag' (Joh 1:39) ... 'die volgende dag' (1: 43) ... 'op die derde dag' (Joh 2: 1)! Ridderbos (1987: 123-124) gee 'n mooi oorsig van die simboliese en allegoriese verklarings in resente literatuur wat steeds probeer om 'die derde dag' as eintlik die sewende dag te vertolk. Hy hou egter self vas aan 'n streng historiese verloop van die vermeldings sodat 'die derde dag' beteken 'op die derde dag' na die gesprek met Filippus en Natanael. So verklaar Bruce (1983: 68) en talle ander dit ook, soos die Moffatt-vertaling dit weergee: Two days later'.

Hoewel die historiese en temporele vertolking van die Vierde Evangelis se plek- en tydaanduidings nie sonder betekenis is nie, bly daar tog 'n ongemaklike 
gevoel by 'n mens dat dit nie alles sê nie. Wou hy maar net die verloop van tyd en wisseling van plek aandui? Dan het hy dit nie baie duidelik of ondubbelsinnig aangedui nie.

Die Vierde Evangelis is nie 'n slordige skrywer nie. Wat hy sê, het meer betekenis as wat in tyd en ruimtelike oorwegings opgesluit lê. Agter al sy mededelings vind ons voortdurend die dieper en groter betekenis wat hyself daaraan heg deur die 'merkers' wat hy in sy teks plaas. En hierdie heel éérste vermelding van 'n bepaalde plek in die eerste hoofstuk is geen uitsondering nie; dit stel die reël.

Ons gaan weer terug na die makrostruktuur van die eerste hoofstuk: In Johannes 1: 1-4 gee hy ons 'n bo-alle-tyd-en-ruimte-verhewe mededeling, in die sin van 'voor alle dinge begin het, was die Woord reeds daar: In die hemel'. Vyf verse later (Joh 1: 6) verskuif die toneel na die aarde. Johannes, 'n mens op aarde, word deur God gestuur, opgeroep tot optrede. Ook die mikrostruktuur is uiters betekenisvol: 'n Man het verskyn (êrens op aarde), God het hom gestuur, sy naam was Johannes.

Onmiddellik word sy rol en funksie aangedui: Hy moet getuie wees, 'n kroongetuie, want hy moet van die lig wat uit die hemel kom, getuig en vir alle tye vaslè. Twee maal word die doel van sy koms en optrede beskrywe met die woorde 'hy moes van die lig getuig' (Joh 1: 7-8). Hy tree nie op kragtens eie gesag en oordeel nie, maar as gestuurde van God (Joh 1: 6). Ewe oorvloedig, byna toutologies, word sy getuienisfinksie onderstreep: 'Hy het gekom om getuienis af te lê' (Joh 1:7) ... 'hy moes van die lig getuig' (Joh 1: 8). God se bedoeling word in die volgende vermelding van Johannes werklikheid: 'Johannes getuig van Hom' (Joh 1: 15). En hierdie werklikheid is: 'dit is die getuienis van Johannes' (OAV Joh 1: 19) toe die

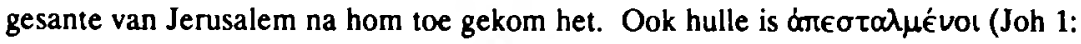
24); in eerste instansie van die Fariseërs, maar in finale instansie van God. Subtiel maak die Vierde Evangelis die verskil aan sy lesers duidelik. Wanneer die gesante praat van die agente wat hulle gestuur het en aan wie hulle rekenskap moet gee, sê

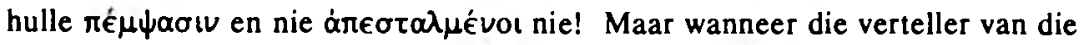

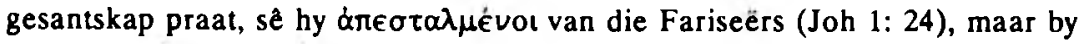

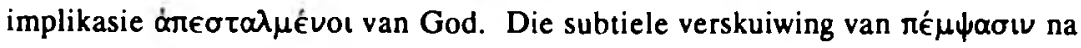

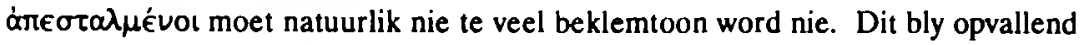

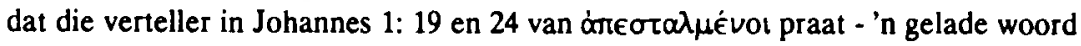
wat 'n amptelike konnotasie dra, terwyl $\pi \hat{\epsilon} \mu \psi \alpha \sigma u v$ gewoon die fisiese feite van stuur beteken. Op grond hiervan is die verteller subtiel besig om God as die finale Een wat stuur aan te dui.

Soos Johannes gestuur is deur goddelike wilsbesluit, so is ook hulle gestuurdes van God. In die konteks is geen ander motief vir die koms van die afvaardiging nie. Sonder die besef staan hulle sending in die vertelling motiefloos. Hoe die motief sy 
volle inhoud gegee word, lees ons in die slot van die proloog en die onmiddellike voortsetting van die verteller (Joh 1: 18 en 19). Die proloog sluit af met die mededeling dat niemand ooit God gesien het nie, maar dat $\mathrm{Hy}$ wat 'in die boesem van die Vader is' (OAV), dit Hy is wat God verklaar.

Deur nog so 'n subtiele werkwoordwisseling van woorde, wat basies sinonieme is, dui die verteller die verskil in die wese en funksie van Johannes en Jesus die

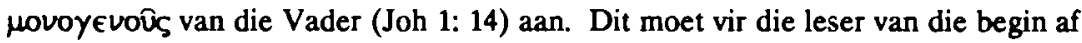
duidelik wees dat Johannes getuig maar Jesus verklaar! Dat die hele vertelling

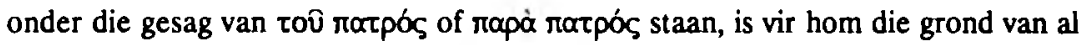
die gebeure.

Daarom staan die gebeure (Joh 1: 1-28 en 1: 29-34 w) nie konteksloos as 'n slotopmerking oor dit wat 'in Betanië gebeur het' (Joh 1:28) nie, maar as 'dit wat by die Vader gebeur het'! Dat Johannes oorkant die Jordaan in Betanië doop, is nie slegs 'n geografiese aanduiding nie maar ' $n$ teologiese bepaaldheid. Johannes 1: 28 is die brug tussen die vertelling oor die gesante en die openbaarmaking wat volg. Anderkant die brug maak Johannes die uitspraak van sy lewe: Daar is die Lam van God! Die gesante kom verneem na die Christus (Joh 1: 25), Johannes openbaar aan hulle die Lam (Joh 1: 29).

Die teologiese betekenis van geografiese aanduiding is by die Vierde Evangelis nie vreemd nie. Dit is opvallend dat Johannes die belangrikste aankondiging doen oorkant die Jordaan.

Johannes 1: 28 vorm 'n brug na die voortsetting van die vertelling. Culpepper (1983: 58) noem dit 'internal analepses ... They often serve no more glamorous functions than providing an identification, recollection, or transition which allows the narrative to proceed smoothly'. Die oorgang in hierdie geval is te opvallend om slegs 'n brug te wees om die vertelling vlot verder te voer. Implisiet dui die verteller aan dat die plek waar die hemel en die aarde ontmoet buite die grense van Palestina val. Dit bring natuurlik 'n dualisme mee met 'n universele trek. Vir die Vierde Evangelis is dit belangrik, omdat dit vir hom oor God en die mense gaan en nie net oor God en Israel nie. Hier in die transjordaanse Betanië is die plek wat God bepaal het dat hemel (Joh 1: 1-2; Joh 3: 31: oúpavós) en aarde (Joh 1: 6-8; Joh 3: 31: yî) sal ontmoet. Hier is deur God die plek bepaal waar God en mens moet ont-

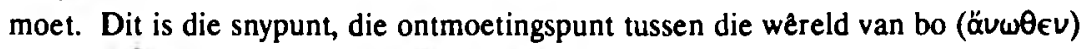

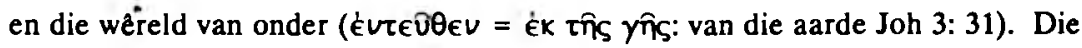
perikoop wat volg (Joh 3: 30-36) op Johannes se laaste getuienis oor Jesus, is 'n vertellerskommentaar oor die betekenis van Johannes se getuienis vir die verstaan van die Een wat uit die hemel gekom het. Hierdie 'dualisme' is 'n grondgedagte van die kerugma van die Vierde Evangelis. 
Vir die verteller is dit belangrik om hierdie raak- en ontmoetingspunt van God en mens op die kaart van die verhaal oor God en die mense, te plaas. Die uitsonderlikheid van die werklikheid wat die Evangelie beskryf, maak hom so 'anders', net soos die Johannese Johannes so 'anders' is. Wanneer die Sinoptiese Evangelies die doop van Johannes vermeld, gaan dit met historiese aanduidings gepaard en word eksplisiet vermeld dat alles gaan om mense tot boete en berou op te roep en hulle dan te doop as teken van die afwassing van hulle sonde (Luk 3: 1-20). Wanneer die Vierde Evangelis dieselfde gebeure verhaal, transformeer hy dit met 'n geheel eie vertelling. .

Wanneer daardie 'volgende dag' (soos deur God bepaal) aanbreek, dan vertel hy nie van mense wat deur hom tot vergifnis van sonde gedoop word nie. Tot hiertoe is slegs sydelings gesê dat hy mense doop (Joh 1: 25-26). Maar, die heel eerste mededeling oor wat Johannes daar by die dooplokaliteit oorkant die Jordaan doen, is nie om te doop nie maar om te getuig: 'Daar is die Lam van God wat die sonde van die wêreld wegneem (Joh 1: 29).

Wat hierna oor die rol en optrede van Johannes volg, is alles gegrond en vloei alles voort uit hierdie allesoortreffende aankondiging. So is die verteller (as vertolker van die kerugma) opgenome met die rol wat Johannes toekom, dat hy nalaat (met opset of andersins) om die eintlike doop van Jesus te vermeld. Vir die verteller stuur alles af op die boodskap van Jesus self: 'Dit verseker Ek julle: Julle sal die hemel oop sien en julle sal die engele van God sien op-en afklim na die Seun van die mens toe' (Joh 1: 51). Die boodskap van Jesus is die teologiese konteks van die hele eerste hoofstuk, maar meer in die besonder van Johannes se cerste optrede en grootste aankondiging van die tema en inhoud van die kerugma van die Vierde Evangelie.

Twee dissipels van Johannes: Johannes 1: $35-42$

Dié gedeelte hang ten nouste saam met die vorige gebeure. Johannes herhaal sy getuienis aangaande Jesus as Lam van God die volgende dag aan twee van sy dissipels toe hy weer daar - by Betanië - gestaan het. Die rede waarom Jesus nog in die omgewing van Johannes se doopplek oorkant die Jordaan vertoef het, word nie vermeld nie. Vanuit 'n narratologiese gesigspunt is dit wel betekenisvol in dié sin dat die eerste dissipels en dus die navolging van Jesus hier begin.

In die lig van wat gesê is oor die Evangelis se pregnante gebruik van plekname en tydsaanduidings, vorm die uitdrukking eintlik die afsluiting van die perikoop, Johannes 1: 29-35, en dui dit veel meer op die volgende moment in die ontvouing van die aankondiging van die Lam. Johannes 1: 29 en 35 vorm 'n inclusio waarvan 
vers 35 die brug en oorgang tot die volgende vertelling is, naamlik van die eerste dissipels van Johannes wat 'oorloop' na Jesus.

Ons moet die uitdrukkings eerder vertolk as 'n teken of merker van logiese suksessie as temporele bepaling. Die bedoeling van Johannes is duidelik nie om 'n kronologiese orde van gebeure te vertel nie, maar te verkondig. Ons sou ook kon praat van verkondigingstyd'.

Deur herhaling van die aankondiging deur Johannes van die Lam van God, kry die uitdrukking 'n nadruklike betekenis. Die kwalifiserende frase wat die sonde van die wêreld wegneem', word nie weer herhaal nie omdat die vertelling van Johannes 1: 29-34 daardie aspek ten volle verklaar het. Nou gaan die verhaal voort: Die lewensbelangrike aankondiging van Johannes word herhaal, sonder kwalifikasie, want nou gaan dit oor sy volgelinge en hulle optrede.

Dit is immers so dat die twee dissipels nie deur Jesus geroep word nie. Hulle word ook nie deur Johannes agter Jesus aan gestuur nie. Hulle volg Hom op grond van hulle eie geloof en oortuiging wat in hulle gewek is deur die getuienis van Johannes. Ons kan aanneem dat hulle nouliks die volle implikasie van die begrip 'Lam van God' toe al sou besef het, maar dat hulle in Hom die komende Een sou sien na wie Johannes verwys het, is aanvaarbaar.

Die vraag waarom die Vierde Evangelie so 'n verskillende berig plaas oor die eerste dissipels wat elders deur Jesus geroep word, laat hom verklaar uit die eie aard en opset van die Evangelis. Hy skrywe nie die Sinoptiese of enige ander tradisie slaafs oor nie; hy transformeer dit, vervang dit met ander aksente en inhoude om aan te pas by sy doel.

In hierdie perikoop, soos in die vorige, staan Johannes voorop as herout van die nuwe bedeling deur die koms van die Lam van God. Alle ander motiewe stel hy ondergeskik aan hierdie basiese uitgangspunt. En omdat by voor staan, is sy volgelinge leerlinge van die 'Rabbi van die Jordaan' Johannes. So immers was Johannes reeds van vroeg af bekend want sy volgelinge gee hom die titel 'Rabbi' (Joh 3: 25). In 'n Evangelie soos Matteus het hierdie gebruik negatiewe implikasies (vgl Matt 26: 25).

Watter hoë aansien hy onder sy volgelinge het, blyk daaruit dat hulle Jesus ook 'Rabbi' noem (Joh 1: 37), juis Hy vir wie hulle voortaan as die Messias, die Christus, sou volg. Vir die verteller word Johannes en Jesus in een raam geplaas, maar nie gelyk gestel nie. Wanneer twee van sy volgelinge hom verlaat en voortaan Jesusvolgelinge word, word nie met 'n woord of gebaar van Johannes teengestaan nie. Dit is dan juis sy getuienis: Die Lam van God wat die sonde wegneem en in Wie hulle hulle geloof moet stel. Dit is volgens die verteller die geloofsdoel van Johannes se getuienis. 
Die uitspraak is vir die Evangelis van ingrypende betekenis: Die twee dissipels is die eerste vrugte van sy getuieniswerk. Daarom is daar by hom geen afkeur nie. Van groter belang is dat Johannes nie bewus is van enige rivaliteit tussen hom en Jesus nie. Hy bly steeds die wegbereider wat onwaardig is om die Een wat na hom kom, se skoenriem los te maak. So vertel die Evangelie dit ook. In sy andersheid teken hy 'n eie veelseggende en indringende gebeure: 'The present passage occupies the position of a bridge in John's narrative, and we see the first disciples moving from Judaism ( $v$ 47) and from John the Baptist ( $v$ 35) to Jesus and his fulfillment of what Judaism and the Baptist meant (Barrett 1972: 149-150).

Deur die redigering van die tradisie deur die Vierde Evangelis kon die eerste volgelinge van Jesus uit die doperkring gekom het (Schneider 1978: 75). Die eerste sendelinge is die eerste oes van die getuienis van Johannes, en terstond word hulle maaiers in diens van Jesus (Joh 12: 21-22). Dat hulle deur Johannes gewerf word en nie deur Jesus self nie, is 'n bydrae tot die besef van die protiel van Johannes wat ons andersins nooit sou gehad het nie.

Wanneer die twee eertydse dissipels van Johannes by Jesus bly (Joh 1: 39), 'daardie hele dag', vind daar 'n totale lewensverandering by hulle plaas. Dat die dag nie ledig deurgebrìng is nie en dat 'n werksaamheid in Jesus veronderstel word, mag ons wel aanneem (Groenewald 1980: 55). Dit blyk uiteindelik uit die haas waarmee Andreas, een van die twee, sy broer Petrus gaan opsoek om aan hom die goeie nuus te gaan meedeel: 'Ons het die Messias gekry' (Joh 1: 41).

Wat van die anonieme dissipel geword het en of hy ook mense na Jesus gebring het, word nie gesê nie. In die lig van die groot aksent wat aan Andreas en Petrus gegee word, is hy van'n mindere orde. Dit spreek van 'n tyd toe die brołrpaas reeds in Christelike kringe bekendheid moes gehad het. Johannes 1: 40 is 'n meedeling van wat vroeër gebeur het. Dit is dus 'storietyd' binne hierdie 'narratiewe tyd'. Dit gee 'n uiters lewendige karakter aan die vertelling.

Dat Johannes die plek gegee word om selfs die eerste dissipels vir Jesus te werf, is in ooreenstemming met die aard van Johannes se beriggewing: Johannes is die getuigende wegbereider. Andreas die eertydse volgeling van Johannes, gaan met haas na sy broer voordat hy enigiets anders doen, om hom vir Jesus te werf (Joh 1: 41). Hiermee is die grondslag van die eerste volgelinge van Jesus gelê. Hier by Betanië is die geboorte van die eerste gemeente van die nuwe verbond wat deur Johannes aangekondig word. Hierin neem Johannes dan ook sy regmatige plek in.

Oorkant die Jordaan: Johannes 3: 26

Dat dit alles op 'n bepaalde wêreldpunt gebeur het, gee aan die uitspraak 'daar oorkant die Jordaan' in Betanië sy volle deur-God-bepaalde betekenis. Behalwe vir 
die vermelding van die plek aan die begin en teen die einde van Jesus se openbare loopbaan, word nog 'n keer hiervan gepraat, naamlik in die gesprek van die volgelinge met Johannes. Die gesprek vind plaas by die gewone doopplek: By Enon naby Salim. In hierdie vermelding van die plek oorkant die Jordaan, dien dit as aanleiding tot en inleiding op die getuienis van Johannes. Dieselfde betekenis en motiewe bepaal ook die konnotasie hier.

Die twee hooffigure staan hier langs mekaar, nie soseer as individue nie, maar veel meer as representante: Die Een van die hemel, die ander van die aarde. Die verhouding tussen die 'Een' en die 'ander' gee die verwysingsraamwerk vir die getuienis van Johannes aan. Die verhouding is 'n ontmoeting, maar ook 'n duidelike en finale onderskeiding van die hemelse en die aardse. In die eerste hoofstuk is daar nog 'n mate van samevloeiing van die vermelding van die persone en werk van Johannes en Jesus, maar hier word die onderskeid tussen hulle duidelik uitgespel en wel by monde van Johannes. Die topografiese aanduiding wat strategies aan die begin en die voortsetting van Jesus se loopbaan geplaas word, gee aan die pleknaam die teologiese diepte van die ontmoeting van twee wêrelde, die een van God, die ander van die mens. In hierdie geval is die aanduiding in die mond van die dissipels. In die eerste perikoop was dit 'n vertellersuitspraak, soos ook in die laaste perikoop. Hoewel dit hier in die mond van die Johannesvolgelinge in die vertelling voorkom, is dit nietemin net so veelseggend. Vir die dissipels is dit slegs ' $n$ verwysing na ' $n$ oord. Vir Johannes het die plek 'n groter en dieper funksie: Die plek is self ook 'n 'herout' van groter dinge. Daarom kry ons so 'n diepsinnige antwoord op 'n vraag wat nie meer verwag as antwoord op 'n konkurrensieprobleem nie. 'Oorkant die Jordaan' is nie konkurrensie nie maar ontmoeting.

\section{Terug in Betaniê: Johannes 10: 39-42}

Die tweede en laaste keer dat die Evangelis teruggaan na die plek oorkant die Jordaan, word in hierdie gedeelte beskryf sonder die toevoeging dat die plek se naam Betanië was. Die feit dat hy duidelik die plek oorkant die Jordaan identifiseer 'as die plek waar Johannes vroeër gedoop het', maak dit duidelik dat hy Betanië bedoel en nie Enon naby Salim nie. Dat hy Betanië nie ook vermeld nie, is waarskynlik te doelbewus om verwarring met die Judese Betanië, wat die toneel van die volgende vertelling is, te voorkom.

Die terugkeer na hierdie plek, is vir Johannes nie slegs om 'n toevlugsoord en heenkome vir Jesus te vind nadat die Jode Hom probeer gevange neem het nie (Joh 10: 39). Die gebeure word nader beskryf en blyk dan net so betekenisvol as die eerste vermelding van die plek in die vorige paragraaf. As hy dit bloot as 'n gerieflike toevlugsoord beskou het, staan die kwalifisering daarvan byna konteksloos 
op die plek. Die vermelding dat hy 'teruggekeer' het hierheen, is veelseggend. In die eerste toneel het Johannes die begin van die openbare optrede van Jesus beskryf. Dit het met sy doop en ontvangs van die Heilige Gees gepaard gegaan. Nou met die tweede en laaste vermelding berei die Evangelis die leser voor dat na veel belewenisse in die openbaar, is Jesus besig om sy loopbaan in die openbaar af te sluit.

Die laaste vers van hoofstuk 10 is 'n duidelike grens, 'n sesuur in die lewe van Jesus. Met hierdie vermelding is echter tevens een einde gekomen aan Jexus' optreden onder het volk. Van nu af zou Hijzich niet meer in het openbaar in Judea vertonen, alvorens Hij zijn laaste reis, om deel te nemen aan het komende pascha zou aanvaarden (Ridderbos 1987: 438). Hiermee dui die Evangelis die begin en die einde van Jesus se openbare werksaamhede aan.

Soos wat dit roemryk aanvanklik begin het, word dit ten einde gebring. Ten spyte van veel en steeds groeiende teenstand, en die feit dat Hy gevangeneming moet ontvlug, is sy werk nie sonder vrug nie. Steeds stroom mense na Hom toe en kom hier tot geloof in Hom (Joh 10: 42). Die geloof wat Hy voortdurend van die Jode gevra het, en tog nie gekry het nie (Joh 10: 25), ontvang Hy nou van 'n ongekwalifiseerde groep mense ('baie mense').

Die meedeling hiervan is 'n vermelding, nie 'n beskrywing nie. Wat Jesus gedoen het of gesé het, word nie genoem nie, slegs dat baie mense op hierdie plek ('daar') tot geloof gekom het. Vir die verteller is dit nie van belang nie.

Wat wel vir hom van belang is, is die aankondiging as 'n plegtige verklaring dat dit alles gebeur het waar Johannes vroeêr, dit wil sê die eerste keer dat Jesus en Johannes ontmoet het, gedoop het voordat Hy na Enon by Salim vertrek het. Vir oulaas verskyn die twee figure op die toneel en plaas die verteller hulle in dieselfde raam. Met groter eer kon hy Johannes nie gehuldig het nie: Hy staan as getuie van Jesus van begin tot einde.

Teen dié tyd het Johannes waarskynlik reeds die marteldood gesterf. Hy het van die toneel verdwyn en Jesus bly alleen staan by Betanië oorkant die Jordaan. In die perikoop wat volg, by die ander Betanië, vind die hoogtepunt van Jesus se bediening plaas: Die opwekking van Lasarus. Daardeur word die finale onderskeid tussen die hemelse en die aardse aangedui. Vir die verteller is die betekenis van Johannes egter te groot om in die vergetelheid te laat vergaan. Selfs by herinnering leef hy steeds as die getuie langs Jesus. Oral waar die evangelie verkondig sal word, sal Johannes steeds genoem word. So kry hy 'n ereplek wat weinig ander beskore is.

Hieroor wil die verteller ons nie in die duister laat nie. Die kort mededeling

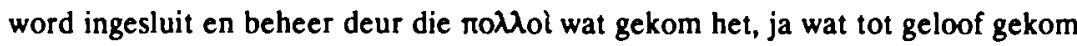
het (Joh 10: 41-42). Veelseggend staan heel aan die einde ékê : 'daar'. 
Wat dár gebeur het, is niks minder nie as die ontmoeting tussen hemel en aarde in Jesus van Betanië oorkant die Jordaan. Vanuit die hemel getuig God in sy Gees, op die aarde, hfer, getuig Johannes dat Hy die Lam is wat die sonde wegneem. Die kontinuĩteit van hierdie getuienis verwoord Reim (1988: 75) in die kol met die volgende: Jesus ist der Zeuge des Vaters. Der Taufer ist der Zeuge Jesu ....

Dat Johannes as ' $t$ ware uit die dood teruggeroep word om nog eenmaal langs Jesus te staan, is die sluitsteenbewys van sy grootheid. Die verteller laat die skare wat gekom het, die inisiatief neem om te getuig, nie Jesus nie. In die Evangelie sal ons tevergeefs soek na ' $n$ beoordeling of uitspraak van Jesus oor Johannes. Dit le nie aan Jesus nie, maar aan die verteller.

Johannes is vir die verteller steeds die 'bemiddelaar' van die heilsgawe sodat 'almal deur hom tot geloof sou kom' (Joh 1: 7). Daarom gaan die uitspraak wat hulle oor Jesus het, nie direk na hom nie maar via 'n bevestiging oor wat Johannes gedoen het. Selfs na sy dood, so wil die Evangelis ons met die gebeure op die plek laat verstaan, getuig Johannes steeds van die lig en kom mense deur hom tot geloof.

Die 'alles' wat van Johannes gesê is (Joh 10: 41), word nie uiteengesit nie. Dit bring op die manier die groot omvang van die werk van Johannes veel beter tot uitdrukking as wat individuele woorde en dade sou getuig. Dit vat 'alles' wat hy gese het, saam en toon dat hy dit wat aan hom aanvanklik opgedra is, voltooi en met groot gevolg afgelé het. Dat Johannes meer gedoen en gesé het as wat die Evangelie vermeld, kan ons stellig uit hierdie berig anneem. Dit is egter nie die bedoeling van die outeur om dit te belig nie. Die belangrikste vir hom is dat Johannes steeds voor en langs Jesus moet staan wanneer Hy sy loopbaan ten einde bring.

Hy vind dit nodig om by te voeg dat Johannes dit alles bereik sonder dat hy 'n enkele wonderwerk verrig het (Joh 10: 41). Wat hy bereik het, het hy suiwer deur die woorde van sy getuienis bereik. Wat hy te sê gehad het, het die vrugte afgewerp wat God bepaal het dat dit moet hê: Geloof in die Lam van God. Die wonder van die getuienis is groter as soveel wondertekens wat 'n Elia of ander profeet sou kon doen. Johannes was van begin tot einde 'n getuie, nie 'n doper of 'n wonderwerker nie. Sy woorde was in meer as een opsig profeties. Ook vir die verteller is daar 'n profetiese vergesig in die gebeure. Subtiel verwys hy met die berig na die komende dood van Jesus maar ook deur die lewende herinnering aan Johannes na die triomf van sy opstanding. Die berig is as 't ware ' $n$ voorskou op die vertelling wat nou volg. Dit is die brug van die een bedeling na die ander. Dit weerspieël die dood van Lasarus (Joh 11: 1-16). Die dood van Lasarus is vir Jesus se volgelinge so 'n ontmoeting dat Tomas uitroep: 'Kom ons gaan ook, sodat ons saam met Hom kan 
sterwe' (Joh 11: 16). Maar vir Jesus is die dood nie die finale woord nie. Hy sê: 'Ons vriend Lasarus slaap, maar Ek gaan om Hom wakker te maak' (Joh 11: 11).

Die dood van Lasarus en sy opwekking deur Jesus is die spieëlbeeld van sy eie dood en opwekking. Dit is nie sonder betekenis nie dat dit juis Tomas is wat so geredelik die dood aanvaar, maar die een is wat so moeilik die opstanding kan verwerk!

Nie sonder betekenis nie, is ook die dood van Johannes wat hier in herinnering geroep word as voorspel tot die dood van Jesus. En soos Johannes in die beriggewing en vermelding lewe, alhoewel hy reeds gesterf het, is meer as net voorspelling van Jesus se opstanding: Dis die waarborg daarvan. So waarborg die getuie van Jesus ook sy oorwinning van die dood deur Jesus.

Die verteller gaat niet eerder over tot het tweede en laatste hoofddeel van zijn evangelie alvorens Jezus nog eenmaal in het licht van zijn grote door God gezonden getuige, 1: 7 geplaatst te hebben. Dit laatste woord van het eerste deel is tevens de inzet van het tweede (Ridderbos 1987: 439).

By geen leser behoort dit verby te gaan dat Betanië oorkant die Jordaan die inleiding en gang is na Betanië duskant die Jordaan in Judea, die dorp waar Maria en haar suster Marta gewoon het nie. Die groot heilsbetekenis van die plek is vir die verteller die eerste en laaste woord oor Johannes, die getuie van Jesus. Opnuut word ons getref deur die diep en ryk betekenis van plekname en tydsbepalings deur die verteller van hierdie Evangelie. Wie slegs historiese ankers soek en tye wil bereken, sien weinig meer as doopplekke en toevlugsoorde. Wie kyk met die verteller se oë, sien meer as wat hy ooit kon vermoed: Hy sien die oop hemel en die engele van God op- en afklim na die Seun van God, die Lam, die Seun van die mens.

Die graf van Johannes is vir ons onbekend, net soos die plek van sy grootste roem. Maar as ons hom 'n laaste rusplek moet gee, dan is dit hier oorkant die Jordaan in Betanië.

Self het hy in sy lewe vir hom geen eer of eerbewys opgeëis nie: Hy was tot sy dood die een wat nie waardig is om Sy skoenriem los te maak nie, maar op aarde is daar nie 'n groter getuie as hy nie. Is dit nie sy betekenis in die Christelike kerugma nie? Johannes is op hierdie plek 'n paradigma vir die geloof van almal wat deur sy getuienis tot geloof in Jesus sou kom.

Barrett verwoord die plek wat dié getuie toekom met woorde wat gerus ten volle aangehaal kan word: 
The Baptist refused all titles and honours, and would be nothing but a voice announcing the presence of the Christ. Similarly his activity was in itself void of power, a mere washing with water ... but like his words it had pointed forward to living water, the Spirit, which Christ gave. John gives no account (except 1: 26f, 29) of what the Baptist said about Jesus; he means in effect that Jesus fulfilled the Old Testament in the person and predictions of its last and greatest representative (Barrett 1972: 321).

\section{Literatuurverwysings}

BARRETT, CK [1955] 1972. The Gospel according to St John: An introduction with commentary and notes on the Greek text. London: SPCK.

BRUCE, FF 1983. The Gospel of John: Introduction, exposition and notes. Basingstoke: Pickering \& Inglis.

CULPEPPER, RA 1983. Anatomy of the Fourth Gospel: A study in literary design. Philadelphia: Fortress.

GROENEWALD, EP 1980. Die Evangelie van Johannes. Kaapstad: NG Kerk Uitgewers.

HAENCHEN, E [1980] 1984. John 1. Transl by RW Funk. Philadephia: Fortress.

METZGER, BM 1975. A textual commentary on the Greek New Testament. London: UBS.

REIM, G 1988. Zur Lokalisierung der johanneischen Gemeinde. $B Z$ 32, 72-86.

RIDDERBOS, HN 1987. Het Evangelie naar Johannes: Proeve van een theologische exegese, Deel 1. Kampen: Kok.

SCHNEIDER, J 1978. Das Evangelium nach Johannes. Berlin: Evangelische Verlag. (ThHK). 